\title{
Making Youth Entrepreneurship Work in Sub-Saharan Africa: Some Factors of Success
}

\author{
Maria Sabrina De Gobbi* \\ International Labour Organization, Geneva, Switzerland \\ Email: degobbi@ilo.org
}

Received 5 July 2014; revised 4 August 2014; accepted 25 August 2014

Copyright (c) 2014 by author and Scientific Research Publishing Inc.

This work is licensed under the Creative Commons Attribution International License (CC BY). http://creativecommons.org/licenses/by/4.0/

(c) †) Open Access

\section{Abstract}

The need to foster private sector development and to combat youth unemployment has made youth entrepreneurship a very attractive option. The present paper tries to identify key factors determining successful entrepreneurship especially in developing countries in Sub-Saharan Africa, starting from evidence from both poor and rich economies. Primary and secondary data from the International Labour Organization as well as secondary data from other institutions have been used. It appears that a young entrepreneur aged 25 - 34, well-educated, with a strong social capital and living in a country with a culture favourable to entrepreneurship and where there are positive perceptions of the attitude of the youth towards entrepreneurship is more likely to be successful than other young entrepreneurs.

\section{Keywords}

Youth Entrepreneurship, Sub-Saharan Africa, Youth Self-Employment, Malawi, Zambia

\section{Introduction}

All over the world, in rich as well as in poor countries, the public sector is facing enormous financial challenges and cannot be perceived as the only and actual engine of economic growth and development. The potentially beneficial role of the private sector in sustainable development is being increasingly recognized [1]. It is mainly the private sector that "invests, innovates and trades" [2]. Responsible private initiatives are hence to be fostered and supported on a global level.

Youth unemployment is a widespread phenomenon, which is a major concern for rich and poor governments alike. Youth entrepreneurship is one of the remedies which is often advocated both to create employment for the

\footnotetext{
*The author is an economist working at the International Labour Organization. However, the opinions expressed are those of the author and do not necessarily reflect those of the ILO.
} 
youth and to promote private sector development. This was recently stated also by the UN Secretary-General, Mr. Ban Ki-Moon, during his visit at the International Labour Organization in Geneva on 18th June 2014 [3]. However, obstacles to the successful implementation of youth entrepreneurship persist along with numerous cases of failures. It may therefore be useful to try and shed some light on limiting factors for young entrepreneurs and on how some existing barriers can be overcome, starting from empirical evidence.

The objective of the present paper is twofold. First, some key factors which can foster successful youth entrepreneurship will be identified, based on findings mainly from some Sub-Saharan African countries, but also from Europe and North America. Then, some barriers experienced by young entrepreneurs in Sub-Saharan Africa will be described, focusing in particular on access to finance, which is a critical problem. Possible solutions to overcome that obstacle will be presented, starting from evidence from poor as well as from rich countries. Some considerations on the economic sectors where young entrepreneurs operate will conclude the discussion.

The questions that the present paper addresses are:

- What are conditions determining successful youth entrepreneurship?

- How do young entrepreneurs cope with their major obstacle to doing business, namely, limited access to financial services?

- What are the sectors where young entrepreneurs are active?

These questions will be answered using primary and secondary data from the International Labour Organization (ILO) as well as secondary data from other institutions.

Youth unemployment is a global issue, but it is a major concern particularly in some developing countries where populations are on average very young. This is why the potential of youth entrepreneurship will be addressed principally for developing countries first, with emphasis on overcoming barriers to its development. The principal data come from recent ILO reports in some Sub-Saharan African countries, especially Malawi and Zambia.

As more detailed information on youth entrepreneurship is available in rich countries rather than in poor ones, in the last section of the paper, data on young entrepreneurs in Veneto, a region in North-Eastern Italy, will be used. This region has been chosen because it is one of the most economically dynamic and successful one in the European Union and very specific statistical data on young entrepreneurs are available.

\section{Some Information on Youth Entrepreneurship in Sub-Saharan Africa}

According to the 2013 Global Entrepreneurship Monitor/Youth Business International (GEM/YBI) youth entrepreneurship report, of all the regions in the world, the highest proportion of potential youth entrepreneurs is to be found in Sub-Saharan Africa (60\%). It is however to be noted that $32 \%$ of these young individuals are necessity-driven entrepreneurs, which means that entrepreneurship is perceived as a survival strategy and not as a business opportunity [4]. Considering specific data primarily on Malawi and Zambia may disclose some differences on youth entrepreneurship among Sub-Saharan African countries.

In general, Sub-Saharan Africa has a very young population. A recent ILO study on eight Sub-Saharan African countries ${ }^{1}$ reveals that young people account for about $20 \%$ of the total national populations [5]. Malawi has a very young population, with a median age of 17 years in 2009. A recent ILO survey reveals that about $63 \%$ of young Malawians are self-employed mostly as own-account workers, and more rarely as employers with employees (only about 2\%). The largest proportion of the young self-employed (35.6\%) claimed that they chose self-employment to have greater independence. These findings indicate that young entrepreneurs in Malawi are slightly more opportunity than necessity driven. It is to be added that, of those young Malawians who said they were very satisfied with their jobs, $75.4 \%$ were self-employed [6].

The Zambian population is also rather young, with almost 75\% of them being under 35 years of age in 2010 . A recent ILO survey shows that about $30 \%$ of young Zambians are self-employed mostly as own-account workers, and less frequently as employers with employees (about 6\%). Of all surveyed young self-employed, 53.2\% said they became self-employed because they could not find any paid work, while $22 \%$ said that they chose self-employment to have greater independence [7]. In the case of Zambia, it is possible to conclude that youth entrepreneurship is more necessity than opportunity driven. This can be explained by the fact that in Zambia waged employment is more widespread than in Malawi. Considering specific data on youth from recent ILO

\footnotetext{
${ }^{1}$ Benin, Liberia, Madagascar, Malawi, Republic of Tanzania, Togo, Uganda and Zambia.
} 
surveys, in Zambia 39\% of the youth were in waged employment as opposed to only $20.8 \%$ in Malawi [5]. In line with this latter finding, in Zambia enterprises run by self-employed youth are larger in size than in Malawi, with a higher proportion of businesses employing more than one person.

\section{What Are the Conditions Determining Successful Youth Entrepreneurship?}

Several factors play a role in youth entrepreneurship. Some of them are:

- perception of, and attitude towards, youth entrepreneurship;

- entrepreneurial culture;

- education level;

- age; and

- social capital.

The following is a description of the conditions that those factors must meet in order for youth entrepreneurship to be more likely to succeed.

\subsection{A Positive Perception and Positive Attitude}

A positive perception about being able to undertake a specific task or activity is very likely to lead to a successful implementation of that task or activity [8]. This is why having a positive perception and attitude towards entrepreneurship increases the chances of becoming successful entrepreneurs. The GEM has estimated that individuals who believe that they have the skills necessary to start an enterprise are 4 to 6 times more likely to do business [4].

The same report reveals that the youth in Sub-Saharan Africa have generally high positive attitudes towards entrepreneurship and that doing business is a more common source of employment than in other regions of the world. Entrepreneurship is perceived as a viable career opportunity and the youth are more willing to start a business [4]. The following specific data on some Sub-Saharan countries confirm this finding and shows that positive attitudes and perceptions are stronger in some countries than in others.

About $50 \%$ of the informal trainees interviewed for an ILO study in Malawi claimed that they wanted to start their own business after informal training. According to the same report, in Tanzania the percentage of informal trainees who started their own company is as high as 80\% [9]. A 2009 labour market survey on technical, entrepreneurial, vocational education and training (TEVET) in Malawi reveals that $57.6 \%$ of the interviewed apprentices were willing to engage in self-employment in order to obtain a higher income and level of independence [10].

According to recent ILO school-to-work transition surveys, when asked about their life goals, about $34 \%$ of surveyed young Malawians said that having a good family life was their leading goal, whereas about $29 \%$ of them stated that their primary objective in life was making lots of money [6]. The fairly materialistic view of life and perhaps entrepreneurial attitudes of young Malawians are somehow in contrast with those of surveyed young Zambians, who said that their main life goal was being successful in work (38.5\%), having a good family life $(26.3 \%)$ and making a contribution to society (25.3\%). Interestingly, only $7.2 \%$ of interviewed Zambian current students stated that they wanted to work in their own business or farm as a future job, with only $3 \%$ of them expressing the wish to start their own enterprise. The large majority of them (81.5\%) intended to work for the government [7]. Clearly, positive perceptions towards youth entrepreneurship are more present in Malawi than in Zambia. The same trend can be seen when considering positive attitudes of youth towards entrepreneurship.

As a matter of fact, a 2012 ILO survey on the enabling environment for sustainable enterprises in Malawi reveals that $49.6 \%$ of respondents, including business owners, managers and employees, believed that the attitude of the youth towards entrepreneurship in Malawi was positive or very positive. Of all interviewees, 37\% thought that young men had a more positive attitude towards entrepreneurship than young women, whereas $28 \%$ believed that the opposite was true [11].

A similar survey conducted in 2013 in Zambia discloses a less positive picture for this country. The general attitude among young people (men and women aged 15 - 24) towards entrepreneurship was positive to very positive for $34.2 \%$ of respondents. Interestingly, for the same share of interviewees, it was neutral. Furthermore, over $42 \%$ of respondents felt that young men had a more positive attitude, and about $30 \%$ found that women did. About 22\% thought that attitudes of young men and young women towards entrepreneurship did not differ [12]. 
In Lesotho, when asked about the attitude of young people towards entrepreneurship for a similar ILO survey conducted in $2014,40.6 \%$ of all respondents thought that it was positive to very positive, and $30.8 \%$ believed it was neutral. Half of young respondents (50\%) indicated that it was very positive or positive. However, as respondents get older, the share of positive or very positive perception decreases. Interestingly, young respondents were also much more likely than all others (44\%) to express the view that the youth have negative or sometimes negative attitudes towards entrepreneurship. For the largest share of respondents of all ages (40\%) the attitudes towards entrepreneurship of young men and young women were similar [13].

An ILO survey on the same topic conducted in Swaziland in 2011 reveals that for 30\% of respondents, including employers and employees, the attitude of young women and men towards entrepreneurship was positive, and for $40 \%$ of them it was neutral. Furthermore, surveyed employers and employees found that the attitude of young women and young men was largely similar [14].

Based on the information presented so far, it can be concluded that chances of success of youth entrepreneurship may be higher in those countries with more positive data on the perception and attitude of youth towards entrepreneurship. Figure 1 sums up findings on country perceptions.

\subsection{Entrepreneurial Culture}

Understanding whether there is an entrepreneurial culture which favours business development and private sector growth in a given country is extremely difficult. More than the specific indicators that are regularly measured over time, the most frequently used source of information is stakeholders' perception. Findings from the ILO country assessments of the enabling environment for sustainable enterprises provide useful information in this regard.

Contrary to the positive findings on the attitude and perception of Malawian youth toward entrepreneurship, it seems that in Malawi there is a prevalent culture that does not recognize the value of entrepreneurial activity [11]. Again in contrast with the rather negative picture of perceptions of the attitude of youth entrepreneurship in Zambia, it is observed that in this country a culture favourable to entrepreneurship exists [12]. In both countries, though, entrepreneurial culture seems to be particularly unfavourable to women [11] and [12].

In Lesotho, being an entrepreneur does not bring prestige and youth are not enticed or encouraged to become entrepreneurs. The ILO 2014 survey on the enabling environment for sustainable enterprises reveals that for $53 \%$ of respondents the Lesotho education system and way of living only moderately promote entrepreneurial culture [13].

In order to make youth entrepreneurship successful in a given country, it is important to develop an entrepreneurial culture which promotes business creation and development. This can be done through the organization of specific campaigns, government programmes, education programmes, as well as training activities. Where women are in a particularly unfavourable situation, special measures ought to be taken in order to reach gender equality in entrepreneurial culture.

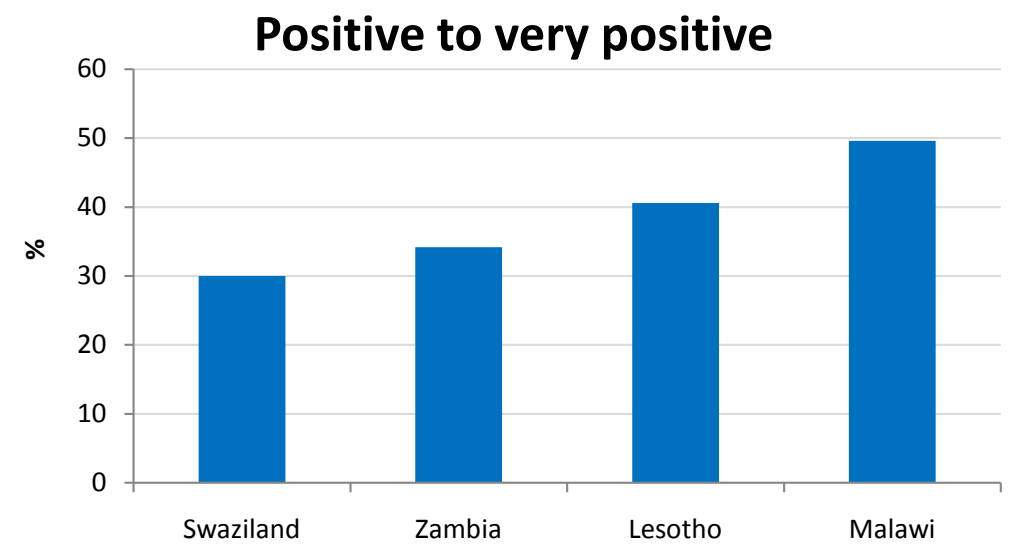

Figure 1. Share of positive perception of youth towards entrepreneurship by country (\%). Source: ILO surveys on the enabling environment for sustainable enterprises. 


\subsection{Education Level}

Findings from an assessment of self-employment programmes for the unemployed in seven industrialized countries $^{2}$ reveal that being well-educated and having a high level of human capital including skills, qualifications and training, are very important characteristics to be successful entrepreneurs [15].

Sub-Saharan Africa is the region in the world with the lowest education levels, with poor literacy and numeracy rates and widespread school drop-outs. Only $45 \%$ of the youth in this region have completed high school compared to over $70 \%$ in all other regions [4]. The already-mentioned 2014 ILO report on eight Sub-Saharan African countries indicates that the average current school participation rate reaches only $41.8 \%$. Only $32.5 \%$ of youth completed primary school and $32.3 \%$ of them left school at below the primary level. The same source reveals that between $1.5 \%$ and $28.8 \%$ of young people in the 8 selected countries have never attended school [5]. Becoming successful young entrepreneurs seems therefore to be particularly challenging in Sub-Saharan Africa. These negative findings on education are confirmed on a country level.

The ILO school-to-work transition survey conducted in Malawi indicates that $54.2 \%$ of surveyed youth had not even attained primary-level education, and only $15.7 \%$ of them had completed education on a secondary level or higher. Moreover, 65.5\% of interviewed young males and 51.8\% of young females had dropped out of school. Another interesting finding, which is not very encouraging for successful youth entrepreneurship in Malawi, is that educated youth are engaged in waged employment more than in self-employment. Less than $1 \%$ of the surveyed young self-employed had university or other tertiary education. They however earned three times more than those youth who were self-employed and had no education [6].

Interestingly, as noted above, in Malawi there seem to be more opportunity-driven entrepreneurs than in Zambia, despite low education levels. The lack of waged employment opportunities in some countries like Malawi may explain why some youth choose to do business. Alternative options may simply be considered as unrealistic, particularly in rural areas. Opportunity-driven motivation for starting an enterprise in some very poor countries should therefore be taken with caution.

The 2010 Zambia Business Survey confirms the idea that education makes good entrepreneurs. It reveals that in Zambia, SMEs with better educated owners are more productive [16]. According to the ILO school-to-work transition survey, the majority of the youth was in school intended to pursue further education in order to improve their employment opportunities. The level of education made a difference also for the self-employed. Earnings of young self-employed with secondary education were about 4 times higher than those of young self-employed with primary education [7].

Education is a major challenge for successful youth entrepreneurship in Sub-Saharan Africa. Shifting from necessity-driven self-employment to opportunity-driven entrepreneurial activity may require strengthening interventions providing education and training to young women and men on one hand, and increasing support to well-educated youth who could become successful entrepreneurs on the other.

\subsection{Age}

According to the 2013 GEM/YBI youth entrepreneurship report, in Sub-Saharan Africa the older youth aged 25 - 34 are more likely than younger individuals to start a business [4]. Moreover, the already-mentioned study on self-employment for the unemployed in industrialized countries shows that male individuals aged around 35 or more have higher chances to survive in self-employment compared to other age groups and to females [15].

Based on these findings, in Sub-Saharan Africa it may be worth focusing on older youth rather than on those aged 15 - 24, as their chances of becoming successful, opportunity-driven entrepreneurs are higher. The young youth seem to be more in need of support comprising education and training.

\subsection{Social Capital}

In poor and rich countries alike, social capital is a pivotal factor of success in self-employment and youth entrepreneurship.

In Canada, friends and family, linkages to the local community and the use of information channels contribute to the success of the self-employed. Family and friends can provide cheap or free labour in critical phases of the business. In the United States, networks with family and friends are key in the enterprise survival [15].

\footnotetext{
${ }^{2}$ Canada, France, Germany, Ireland, Netherlands, United Kingdom and United States
} 
The GEM/YBI youth entrepreneurship report reveals that in Sub-Saharan Africa, for $40 \%$ of surveyed businesses, family and friends represented between $25 \%$ and $100 \%$ of their customers [4]. Family and friends often also provide capital for the business. This was the case for $24.3 \%$ of interviewed youth in Malawi [6] and about $32 \%$ of young Zambian respondents [7] according to the ILO school-to-work transition surveys.

Clearly, those youth who have strong social skills and are integrated in solid social networks, including youth organizations, have higher chances than others to become successful entrepreneurs.

\section{Some Barriers to Youth Entrepreneurship}

The 2013 GEM/YBI youth entrepreneurship report indicates that for the youth in Sub-Saharan Africa, the main barriers to entrepreneurial activity are lack of capital, lack of skills, lack of support and lack of market opportunities [4]. The 2014 ILO report on youth in eight Sub-Saharan African countries reveals that $50 \%$ or more of young entrepreneurs in Benin, Liberia, Malawi and Togo stated that limited access to finance is their principal obstacle to doing business. Competing in the market and shortages of raw materials are two other relevant impediments [5].

The ILO school-to-work transition survey conducted in Malawi reveals that, for $52.2 \%$ of respondents, difficult access to financial services is the principal obstacle that the youth experience in entrepreneurial activity. The second most cited barrier is lack of marketing services, as reported by $10 \%$ of young interviewees [6]. In Zambia, for about $47 \%$ of surveyed young women and men, lack of financial resources is the principal barrier to youth entrepreneurship, followed by market competition with $24.5 \%$ of respondents giving this answer [7].

The information described above clearly indicates that, although access to finance is not the only problem experienced by young entrepreneurs, it is perceived as the main one. It may therefore be useful to explore the issue of access to financial services more in depth in order to see what kind of solutions can be adopted.

\section{How Do Young Entrepreneurs Cope with Their Major Obstacle to Doing Business, Namely Limited Access to Financial Services?}

The ILO surveys conducted for country assessments of the enabling environment for sustainable enterprises in Lesotho, Malawi and Zambia, all indicate that considering men in general, women in general, the youth in general, and young men and young women, the group which has the most difficult access to financial services is the youth in general and young women in particular [11]-[13]. The youth are not trusted because of their lack of experience and because they usually cannot provide adequate collateral. This situation is not at all likely to change as financial institutions apply sustainability criteria and try to reduce risk to minimum levels.

But how do existing young entrepreneurs finance their businesses?

The GEM/YBI youth entrepreneurship report reveals that in all regions of the world 70\% or more of the youth finance their enterprises through family, friends and personal savings. In Sub-Saharan Africa the proportion is the highest, with $77.7 \%$ of young people using such sources of funding [4]. Between one-fifth and one-third of young entrepreneurs in the eight Sub-Saharan African countries considered in the 2014 ILO report did not need any money to start their business. Personal savings is the main source of funding in all countries except in Liberia and Zambia where higher shares of young entrepreneurs receive money from family and friends [5].

The ILO school-to-work transition surveys provide more detailed information on a country level. In Malawi, $27 \%$ of young entrepreneurs said no money was needed to start their business. For about $42 \%$ of them, personal savings was the source of funding (a hint at the small scale and likely precariousness of the venture), and for $24.3 \%$, friends and family provided financial resources. Only $4 \%$ of young entrepreneurs received funding from formal financial institutions [6]. The situation is very similar in Zambia, where $20.2 \%$ of young entrepreneurs reported that no financing was needed, about 32\% borrowed money from family and friends and almost 31\% used their own savings [7]. Figure 2 illustrates these findings.

Rather than trying to access financial services at any rate, it may be wiser to better understand what kind of business can be created and developed with scarce resources. What kind of enterprises can be developed with possibly small starting capital coming from personal savings or family and friends' contributions? The following section will address this issue.

\section{What Are the Sectors Where Young Entrepreneurs Are Active?}

According to the 2013 GEM/YBI report, in all regions of the world the young youth are more likely than the 


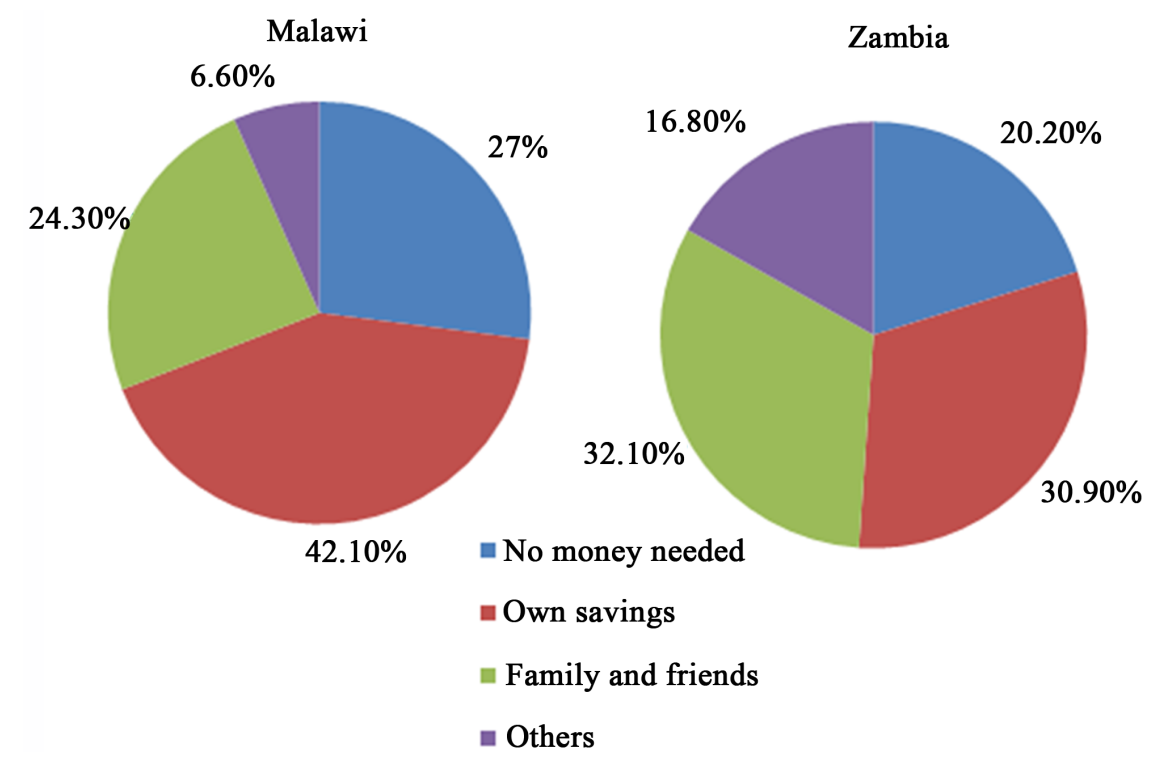

Figure 2. Sources of funding to start a business for young entrepreneurs by country (\%). Source: ILO school-to-work transition surveys.

older youth and adults to develop a business in the retail and trade sector. This is due to the low start-up capital and low level of business skills which are required. Competition within the retail sector is often very high and may become a major obstacle to doing business as shown in Section 4 above. A self-employed job in this sector may therefore be one with a short duration and resulting in low income. It may nonetheless be an excellent learning experience thanks to which useful personal and business skills can be developed for future, better employment [4].

It may be interesting to examine information on young entrepreneurs by sector from Malawi, Zambia and Veneto, an economically very dynamic region in North-Eastern Italy with about 5 million inhabitants. This latter region has been chosen because specific data on young entrepreneurs were available, and because it may be useful to compare youth entrepreneurship in two rather poor countries to that of a high-income area. The young entrepreneurs considered for Malawi and Zambia are 15 to 29 years old and operate largely in the informal economy. The youth considered for Veneto are 18 to 29 years old and their businesses are formally registered as sole proprietorship.

The first observation which ought to be made is that, as indicated in the 2013 GEM/YBI report, trade and retail is indeed the sector with the highest share of young entrepreneurs belonging to the young youth in the three cases (31.7\% in Malawi, $42.7 \%$ in Zambia and 26\% in Veneto). Only in Malawi, a low-income country, agriculture records a higher proportion of young entrepreneurs than retail and trade (51.3\%). Manufacturing is another sector which registers a slightly higher share of young entrepreneurs compared to others in all three cases (7.8\% in Malawi, $4 \%$ in Zambia and 7\% in Veneto). More young entrepreneurs are active in the construction sector in Veneto (23.5\%) than in Malawi (2\%) and Zambia (3.5\%). As the GEM/YBI 2013 report indicates, the internet as a means to do business is underutilized in Sub-Saharan Africa [4]. This is certainly linked to poor education levels and poor ICT infrastructure in Malawi and Zambia and is reflected in Table 1, where these two countries record shares of young entrepreneurs close to zero in "information and communication" whereas Veneto registers a proportion over $2 \%$. The same can be said about "finance and insurance" where the two African countries register levels close to zero and Veneto reaches a share of $3.7 \%$.

Clearly, as Table 1 indicates, young entrepreneurs are more spread among sectors in Veneto, a high-income more diversified economy, than in Zambia, a lower middle-income country, or Malawi which is a low-income state where agriculture is definitely the main source of employment. It is to be added that young entrepreneurs in all three cases seem to be engaged in labour-intensive economic activities requiring a low level of skills and possibly low start-up capital. Furthermore, although in Veneto informal employment is not a completely unknown phenomenon, in Malawi and Zambia young entrepreneurs are almost entirely operating in the informal economy under extremely poor and precarious working conditions. 
Table 1. Youth entrepreneurship (15 - 29 years of age) by sector and by country (\%).

\begin{tabular}{|c|c|c|c|}
\hline & Malawi & Zambia & Veneto \\
\hline Agriculture & 51.34 & 20.56 & 8.95 \\
\hline Mining & 0.36 & 0 & 0 \\
\hline Manufacturing & 7.80 & 3.92 & 7.01 \\
\hline Electricity, gas and water & 0 & 0.19 & 0.04 \\
\hline Water supply & 0 & 0.67 & 0.03 \\
\hline Construction & 2.00 & 3.54 & 23.48 \\
\hline Retail and trade & 31.68 & 42.65 & 25.91 \\
\hline Transport & 1.74 & 1.84 & 1.93 \\
\hline Accommodation & 0.50 & 1.92 & 7.36 \\
\hline Information and communication & 0.30 & 0.86 & 2.11 \\
\hline Finance and insurance & 0.12 & 0 & 3.72 \\
\hline Real estate & - & - & 1.25 \\
\hline Technical and scientific professional activity & 0.41 & 1.15 & 3.58 \\
\hline Administrative & 0 & 0.31 & - \\
\hline Renting and travel agencies & - & - & 3.50 \\
\hline Education & 0.36 & 0.91 & 0.16 \\
\hline Health & 0 & 0.02 & 0.17 \\
\hline Arts, sports and entertainment & 0.15 & 2.65 & 0.84 \\
\hline Other services & 2.46 & 14.20 & 7.69 \\
\hline Private households and non-classified & 0.79 & 4.60 & 2.26 \\
\hline Total & 100 & 100 & 100 \\
\hline
\end{tabular}

Sources: ILO School-To-Work Transition database (2012); Unioncamere del Veneto (2013).

\section{Conclusions}

Based on the information provided so far, a young entrepreneur aged 25 - 34, well-educated, with a strong social capital and living in a country with a culture favourable to entrepreneurship and where there are positive perceptions of the attitude of the youth towards entrepreneurship is more likely to be successful than other young entrepreneurs. These potentially successful young entrepreneurs, women and men alike, should be given special attention and support in order to increase the number of opportunity-driven individuals as opposed to the necessity-driven ones in poor countries.

Youth entrepreneurship for the young youth often seems to have the characteristics and function of a learning experience, where individuals acquire and develop business and personal skills. The support provided to young people in this case should therefore be much more focused on the provision of education and training for the acquisition of new skills, which could increase the chances of success for them.

Limited access to finance for young entrepreneurs should be seen more as a feature of doing business for the youth than as a constraint. The youth, in particular the young ones who are under 25 years of age, should focus on economic activities which require limited start-up capital, as is often already the case. Financial resources should nonetheless be made available to older youth with the characteristics of potentially successful young entrepreneurs and to those younger ones who have innovative and original business ideas that could move them out of the highly competitive retail sector, and who have, despite their young age, adequate skills and social capital. 
Youth entrepreneurship is certainly a viable solution against unemployment, but other options in waged employment may sometimes be preferable. At a time when programmes to support youth entrepreneurship are proliferating, one hopes that the information presented in this paper and its few final remarks will help make supportive actions more focused and effective.

\section{Acknowledgements}

The author would like to thank Sara Elder from the Youth Employment Programme of the International Labour Organization for her invaluable comments, and Yves Perardel from the same programme for promptly providing disaggregated data. Deep appreciation is due also to Unioncamere del Veneto for the prompt provision of disaggregated data. The author is particularly grateful to Liliana Neil for editing this paper.

\section{References}

[1] World Bank (2014) Private Sector Data. http://data.worldbank.org/topic/private-sector

[2] International Labour Organization, United Nations Conference on Trade and Development, United Nations Department of Economic and Social Affairs, World Trade Organization (2012) Macroeconomic Stability, Inclusive Growth and Employment. Thematic Think Piece. Geneva. www.un.org/millenniumgoals/

[3] International Labour Organization (2014) Youth Employment: Ban Ki-Moon: Decent Jobs for Youth Are Essential to the Future We Want. http://www.ilo.org/global/about-the-ilo/newsroom/news/WCMS 247414/lang--en/index.htm

[4] Kew, J., Herrington, M., Litovsky, Y. and Gale, H. (2013) Generation Entrepreneur? The State of Global Youth Entrepreneurship. Global Entrepreneurship Monitor (GEM), Youth Business International (YBI).

[5] Elder, S. and Siaka Koné, K. (2014) Labour Market Transition of Young Women and Men in Sub-Saharan Africa. Youth Employment Programme, Employment Policy Department, Work 4 Youth Publication Series No. 9, ILO. Geneva.

[6] Mussa, R. (2013) Labour Market Transition of Young Women and Men in Malawi. ILO Youth Employment Programme, Publication Series No. 4. Geneva.

[7] Chigunta, F., Chisup, N. and Elder, S. (2013) Labour Market Transition of Young Women and Men in Zambia. ILO Youth Employment Programme, Publication Series No. 6, Geneva.

[8] Bandura, A. (1982) Self-Efficacy Mechanism in Human Agency. American Psychologist, 37, 122-147. http://dx.doi.org/10.1037/0003-066X.37.2.122

[9] Aggarwal, A., Hofmann, C. and Phiri, A. (2010) A Study on Informal Apprenticeship in Malawi. Employment Sector, Employment Report No. 9. Skills and Employability Department, ILO Decent Work Team for Southern and Eastern Africa. http://www.ilo.org/wcmsp5/groups/public/---ed_emp/documents/publication/wcms_151254.pdf

[10] Jimat Development Consultants (2009) Malawi Labour Market Survey. Technical, Entrepreneurial and Vocational Education and Training (TEVETA). Lilongwe, Malawi. http://www.tevetamw.com/pdf/Malawi-Labour-Market-Survey-2009.pdf

[11] De Gobbi, M.S. and Anang, R. (2013) The Enabling Environment for Sustainable Enterprises in Malawi. ILO Employment Sector, Employment Report No. 20, Geneva.

[12] De Gobbi, M.S. and Anang R. (2013) The Enabling Environment for Sustainable Enterprises in Zambia. ILO Employment Sector, Employment Report No. 22, Geneva.

[13] International Labour Organization (2014) The Enabling Environment for Sustainable Enterprises in Lesotho. Enterprises Department, ILO, Geneva.

[14] Buckley, G. (2011) Swaziland-The Enabling Environment for Sustainable Enterprises: An EESE Assessment. ILO Employment Sector, Employment Report No. 10, Geneva.

[15] International Labour Organization (2002) Micro-Finance in Industrialized Countries: Helping the Unemployed to Start a Business. Social Finance Programme, Geneva.

[16] Clarke, G.R., Shah, M.K., Sheppard, M., Munro, J. and Pearson Jr., R.V. (2010) Zambia Business Survey: The Profile and Productivity of Zambian Businesses. FinMark Trust; Private Sector Development Reform Programme. World Bank Zambia Country Office, Zambia Business Forum. 
Scientific Research Publishing (SCIRP) is one of the largest Open Access journal publishers. It is currently publishing more than 200 open access, online, peer-reviewed journals covering a wide range of academic disciplines. SCIRP serves the worldwide academic communities and contributes to the progress and application of science with its publication.

Other selected journals from SCIRP are listed as below. Submit your manuscript to us via either submit@scirp.org or Online Submission Portal.
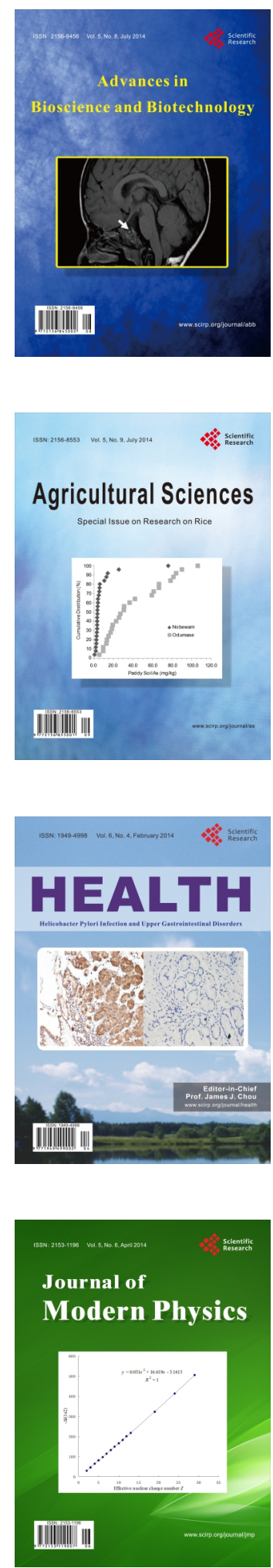
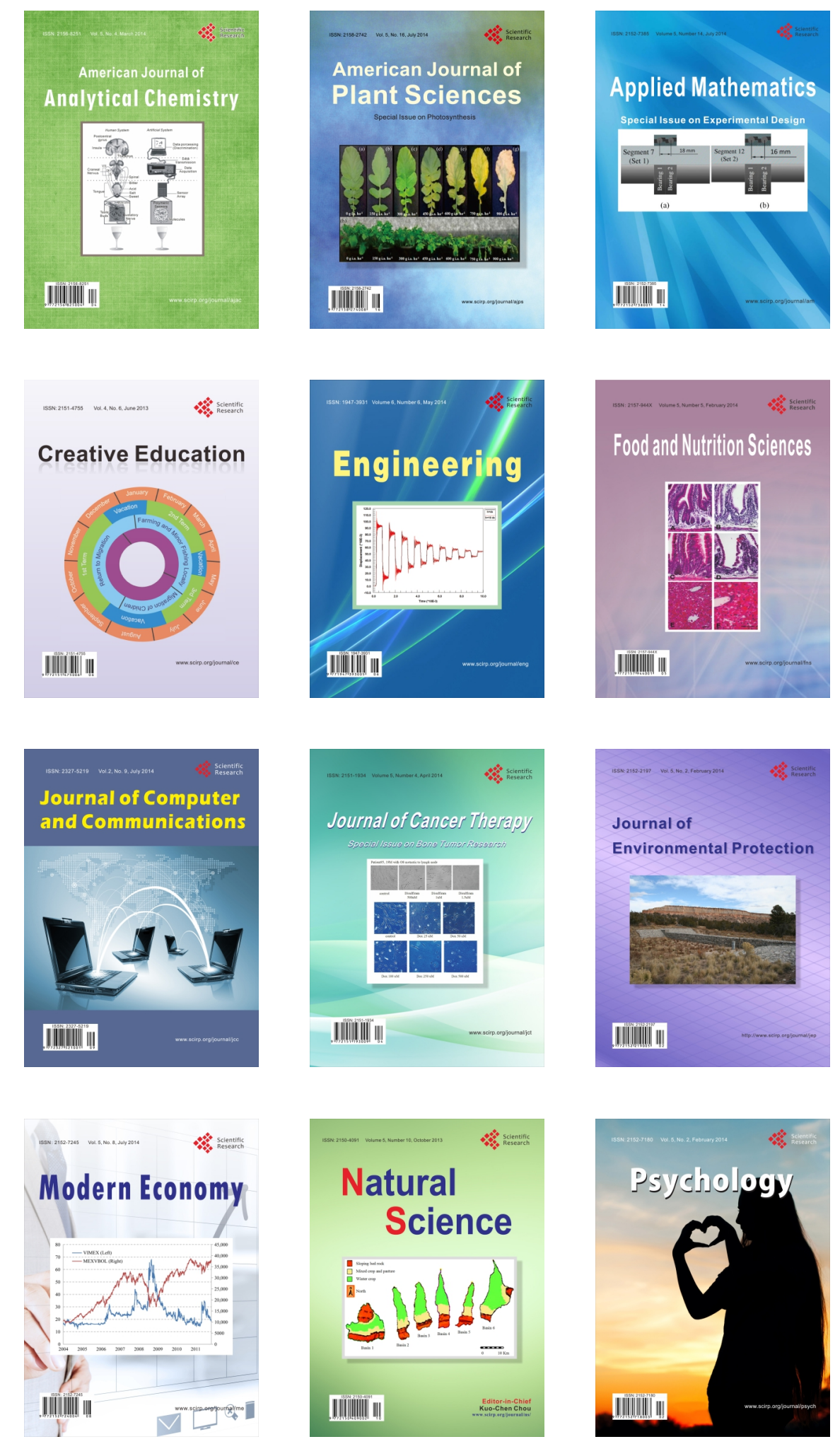